\title{
Are Biomarkers in Reproductive Medicine Reliable?
}

\author{
Hazout $\mathrm{A}^{1}$, Tesarik J ${ }^{2}$, Belloc $\mathrm{S}^{3}$, Cassuto $\mathrm{NG}^{4}$ and Benkhalifa $\mathrm{M}^{5}$ \\ ${ }^{1}$ ATL R\&D Laboratory. 78320 La Vérrière. France and RDP Conseil Paris France \\ ${ }^{2}$ Clinica MARGen Granada SPAIN \\ ${ }^{3}$ Lavergne laboratory. 75016 Paris. France \\ ${ }^{4}$ ART Unit Drouot Laboratory. Rue Drouot Paris France
}

${ }^{5}$ Reproductive Medicine, Biology \& Genetics. University Hospital and School of Medicine. Picardie University Jules Verne. Amiens. France

Submission: October 30, 2018; Published: November 02, 2018

*Corresponding author: Hazout André. 21 Rue Faidherbe 94130 Nogent sur Marne.

\section{Opinion}

Since the advent of the first baby born after invitro fertilization (IVF), clinicians and biologists are searching for reliable markers of embryonic quality before transfer. However, are we not doing wrong by targeting the embryo?

The answer would be easy if the embryo selection, using direct or indirect markers, had not emerged as a form of eugenics; in some countries, a moratorium was requested, essentially by the biologists. At that time, when our technical means of investigation were extremely limited but used without regulation, the civil societies believed to have an obligation of protecting themselves from potential manipulations. The famous precautionary principle which suspended, all substantial progress in terms of embryo research in several european countries for a long time.

Reproductive success, the ultimate goal of which is the birth of a healthy baby, depends on three major factors: the oocyte, the sperm (largely forgotten by pioneers) and the endometrium. To date we have different tools for investigating gametes and endometrium. Before making a list, it is important to remember that, in the 1990s, we needed ten to fifteen oocytes to get a birth (Testart J. et al. unpublished). On the other hand, retrieval of $>15$ oocytes significantly increases the risk of ovarian hyperstimulation syndrome (OHSS) without improving live birth rate in fresh autologous IVF cycles [1,2]. Nowadays, we need also 10 to 15 oocytes to generate a birth [3].

A much more difficult question is whether and how much ovarian stimulation impacts on oocyte competence. Paradoxically, no differences between the stimulated and the natural unstimulated cycles, in terms of pregnancy outcomes, have been demonstrated whereas studies in laboratory animals and IVF patients have shown deleterious effects of high doses of gonadotropins compared with lower ones [4].

And what about embryo freezing? Before the advent of vitrification, the so-called slow embryonic freezing was inefficient in terms of embryo survival and pregnancy. Hence, the clinicians tried to define ovarian reserve markers, considering the oocyte as the "Gordian knot" of the reproduction. Indirect criteria, based on determination of the plasma levels of different hormones, such as FSH, estradiol [5] or inhibin B, proved to be unreliable, and were largely questioned. Dynamic tests of ovarian response to stimulation, (clomiphene citrate, FSH, GnRH agonists ...) intended to refine and complement the assessment based on evaluations carried out at the beginning of a spontaneous cycle. These imperfect tests, were quickly abandoned. Later on, more direct tests have been identified: anti Müllerian Hormone (AMH) and ultrasound-based antral follicle count (AFC), although the latter is operator dependent and thus not quite objective. These markers are considered as complementary, but AMH is now unanimously recognized as the most reliable because of its stability during the menstrual cycle and its predictivity of the ovarian response to stimulation according to the women's age that is the only limiting factor [6,7]. However, except for values close to zero, plasma AMH is not predictive of pregnancy [8]. High AMH levels urge caution because the OHSS risk is higher. The confrontation with other clinical or biological factors remains mandatory for a prognosis [9].

Since recently, sperm quality has been considered not only with regard to sperm ability to fertilize the oocyte, but also in a broader context, including sperm-borne factors involved in the determination of postfertilization events during early embryo development. Accordingly, there is growing evidence for a role of sperm-borne factors in postfertilization embryo development, including the determination of embryo developmental competence and implantation potential, the risk of miscarriage and the appearance of epigenetic diseases, related or not to defective genomic imprinting and potentially transmissible to future generations [10]. This calls for additional responsibilities of both the clinicians and the biologists involved in IVF procedures. 
We know today that genetically diverse spermatozoa coexist in the same ejaculate, and the choice of the spermatozoa to be used for fertilization can thus influence the fertility chances and embryos quality of the resulting embryos [11]. Furthermore it's all the more important when it comes to injecting only one spermatozoon in ICSI.

The spectacular oocyte fertilization rate achieved by intracytoplasmic micro-injection of a single spermatozoon (ICSl), in cases of severe oligo-asthenoteratospermia, [12] is "the tree hiding the forest". Do we still miss reliable markers of epigenetics risk factors markers, which could compromise the prognosis of the conceptus and its descendants?

The study of sperm head morphology [13-15] at very high magnification in real time has started the ongoing debate about the relationship between the presence of large vacuoles in the sperm nucleus and the fragmentation and/or decompaction of nuclear chromatin. Simon et al. [16] think it's important to go back to the data derived from natural sperm selection to improve our invitro practices. Some tests have also been proposed for the oocyte and endometrium evaluation, without having reached convincing results so far. Sakkas and al. suggest to identify the attributes of a spermatozoon capable of migrating through the cervical mucus. Other investigators propose a wider use of metabolomics [17].

The currently increasing interest of biologists in various new aspects of sperm quality contrasts with the traditional view of the spermatozoon as a mere vehicle for male DNA transport into the oocyte, further reinforced by the initial enthusiasm about the success of ICSI. This overenthusiasm led to a false belief that ICSI had definitely resolved all sperm-related problems of fertility. However, the requirement of a "mature and competent" oocyte, on the one hand, goes accompanied by the need for "adequate" spermatozoa, on the other. Unfortunately, we do not know yet how to define each of these two concepts.

Meanwhile, confident in the effect of chance, clinicians continue to transfer at least two embryos taking the risk of multiple pregnancies and their procession of complications. Aware that the age of the oocyte alters its competence at least by the loss of a quarter of the mitochondrial DNA genome [18], many clinics practice the transfer of more than two embryos in women over 40 , leading to a perverse effect of more multiple pregnancies in elderly women.

As to the evaluation of embryo quality, in addition to the conventional static observations on embryonic cell morphology observations on embryo developmental dynamics (Time Lapse Technology) and karyotype study have been suggested. However, these examinations are not possible in certain countries, and the "Time Lapse ", at the best, only rarely allowed deselection of some embryos before transfer [19], because of the lack of definitely validated evaluation criteria. Other studies tended to demonstrate a relationship between embryo cleavage velocity and ploidy. The purpose of these works was to establish an algorithm likely to choose the best blastocyst for transfer; which implies that these authors recommend a prolonged embryo culture until the blastocyst stage, trophectoderm biopsy, and more single vitrified/ thawed blastocyst transfers, during a spontaneous cycle, with faster access to a pregnancy from an euploid embryo.

We let you imagine the heaviness and the price of such a course ! Moreover, serious and justified doubts as to the reliability of the current preimplantation genetic screeening techniques, based on analysis of trophectoderm cells, have recently been formulated by various and independent groups of experts [20,21,22]. Moreover, even some of the initially aneuploid embryos appear to convert to euploid ones by selective elimination of the aneuploid cells through a mitotic spindle checkpoint control leading to multinucleation of the affected cells and preventing them from further development [22]. In view of the serious gaps of the current techniques for determination of preimplantation embryo ploidy, a combination of pronuclear morphology at the zygote stage [23-24], shown to predict embryo ploidy [25], with repeated static evaluation of embryos at the cleavage stages appears to be the best and cheapest way of selecting embryos for transfer.

The real needs of the in vitro human embryo culture have been largely studied for decades. Convincing demonstrations put forward the variable glucose requirements during prolonged culture, serum adjunction, amino acids, and other growth factors [26].

Accordingly, so-called sequential media, then "Globals", were launched on the market, adjusting medium composition to the current needs of the developing embryo. These culture media make it possible to obtain, at best, $43 \%$ of blastocystes, nearly half of them aneuploid, on the $5^{\text {th }}$ day of culture [27]. The seductive idea (80s) to co-culture human embryos on heterologus epithelial cells ( monkey kydney cells : vero cells , tubal and granulosa cells) and then autologous endometrial cells have been successful: more fresh and frozen blastocysts, and, better cumulative pregnancy rates rate per cycle were obtained [28]. However, the risk of prion contamination by, among others, the addition of fetal calf serum, introduced the concept of the precautionary principle, interrupting the practice of prolonged embryo co-culture.

Nevertheless, these culture systems improved the regulation of embryo glucose metabolism, and embryonic waste detoxification, in addition to providing many essential growth factors. In the best of all worlds, there should be opportunities to explore genetic and biomolecular substratum from synthetic prolonged culture media, integrate microfluid systems in the "time lapse ", study metabolomics proteins and free nucleic acids [29] in plasma, follicular, culture media, seminal fluids ...; and the list of potential markers not yet totally validated is not exhaustive. If endometrial functional assays are added, to better evaluate its receptivity, you can imagine the cost of an attempt and potential margin of errors; without forgetting mitochondrial DNA which is nothing else as "fire in the chimney" and energy supplier for growth and embryonic development. Few authors proposes to study it. The building site is so huge! 
It is still necessary to assess the safety of all our explorations and their clinical effectiveness. No clinical study to date has demonstrated a convincing increase of live birth rate on selected large series. The concept of ideal embryo should be added the concept of ideal endometrium; several teams have determined, by genomic studies, the genes overexpressed during the window of embryo implantation [30] but each author gave different list of overexpressed or under expressed genes. Others studied simply IL6 and LIF and other inflammatory cytokines in the endometrium or in the medium of cocultured embryos [31-32].

Finally, associated pathologies such as endometriosis, adenomyosis or some uterine fibroids can interfere. There are no biological or histochemical markers of endometriosis and the presence of nerve fibers in the endometrium would not be specific [33]. Many of the identified cytokines only reflect an "inflammatory or immuno inflammatory state " that is believed to be necessary for embryo implantation, but may turn out to be deleterious in some conditions.

In conclusion, there are currently no reliable prognostic markers for human reproduction. Sperm is more accessible to exploration than the oocyte. The morphological or even genetic evaluation of an embryo does not prejudge its developmental potential and its ability to implant. In addition, the implantation is a dynamic phenomenon that is ethically impossible to explore. We must continue to establish non-invasive criteria, in the plasma or serum, the seminal plasma, the follicular fluid and the endometrium. Promising tracks are under study but not yet validated. Further ambitious studies are needed.

\section{References}

1. Patrizio P, Sakkas D (2009) From oocyte to baby: a clinical evaluation of the biological efficiency of in vitro fertilization. Fertil Steril 91(4): 1061-1066.

2. Steward RG, Lan L, Shah AA, Yeh JS, Price TM, et al. (2014) Oocyte number as a predictor for ovarian hyperstimulation syndrome and live birth: an analysis of 256,381 in vitro fertilization cycles. Fertil Steril 101(4): 967-973.

3. Drakopoulos P, Blockeel C, Stoop D, Camus M, de Vos M, et al. (2016) Conventional ovarian stimulation and single embryo transfer for IVF/ ICSI. How many oocytes do we need to maximize cumulative live birth rates after utilization of all fresh and frozen embryos? Hum Reprod 31(2): 370-376

4. Bosch E, Labarta E, Kolibianakis E, Rosen M, Meldrum D, et al. (2016) Regimen of ovarian stimulation affects oocyte and therefore embryo quality. Fertil Steril 105(3): 560-570.

5. Toner JP, Seifer DB (2013) Why we may abandon basal folliclestimulating hormone testing: a sea change in determining ovarian reserve using antimüllerian hormone. Fertil Steril 99(7):1825-1830.

6. Hazout A, Bouchard P, Seifer DB, Aussage P, Junca AM, et al. (2004) Serum antimüllerian hormone/müllerian-inhibiting substance appears to be a more discriminatory marker of assisted reproductive technology outcome than follicle-stimulating hormone, inhibin B, or estradiol. Fertil Steril 82(5): 1323-1329.

7. Iliodromiti S, Anderson RA, Nelson SM (2015) Technical and performance characteristics of anti-Müllerian hormone and antral follicle count as biomarkers of ovarian response. Hum Reprod Update 21(6): 698-710.
8. Borges E, DPAF Braga, Setti A, Figueira RC, Iaconelli A, et al. (2017) prédiction valeur des concentrations sériques de l' hormone anti-Müllérienne pour la qualité de l' ovocyte, la fertilisation et l' implantation. JBRA Assist Reprod 21(3): 176-182.

9. Li HW, Lee VC, Lau EY, Yeung WS, Ho PC, et al. (2014) Ovarian response and cumulative live birth rate of women undergoing in-vitro fertilisation who had discordant anti-Mullerian hormone and antral follicle count measurements: a retrospective study. PLoS One 9(10): e108493.

10. Sakkas D, Ramalingam M, Garrido N, Barratt CL (2015) Sperm selection in natural conception: what can we learn from Mother Nature to improve assisted reproduction outcomes? Hum Reprod Update 21(6): 711-726.

11. Wang YJ, Li DW, Zhang WL, Zhang RQ, Wang GN, et al. (2012) Correlation of recurrent pregnancy loss with sperm parameters and sperm DNA fragmentation. Zhonghua Yi Xue Yi Chuan Xue Za Zhi 29(5): 602-605.

12. Palermo G, Joris H, Devroey P, Steirteghem VAC (1992) Pregnancies after intracytoplasmic injection of single spermatozoon into an oocyte. Lancet 340(8810): 17-18.

13. Bartoov B, Berkovitz A, Eltes F (2001) Selection of spermatozoa with normal nuclei to improve the pregnancy rate with intracytoplasmic sperm injection. N Engl J Med 345(14): 1067-1068.

14. Cassuto NG, Bouret D, Plouchart JM, Jellad S, Vanderzwalmen P, et al. (2009) A new real-time morphology classification for human spermatozoa: a link for fertilization and improved embryo quality. Fertil Steril 92(5): 1616-1625.

15. Boitrelle F, Guthauser B, Alter L, Bailly M, Bergere M, et al. (2014) High-magnification selection of spermatozoa prior to oocyte injection: confirmed and potential indications. Reprod Biomed Online 28(1): 6-13.

16. Simon C, Sakkas D, Gardner DK, Critchley HO (2015) Biomarkers in reproductive medicine: the quest for new answers. Hum Reprod Update 21(6): 695-697.

17. Agarwal A, Bertolla RP, Samanta L (2016) Sperm proteomics: potential impact on male infertility treatment. Expert Rev Proteomics 13(3): 285-296.

18. Bentov Y, Yavorska T, Esfandiari N, Jurisicova A, Casper RF, et al. (2011) The contribution of mitochondrial function to reproductive aging. J Assist Reprod Genet 28(9): 773-783.

19. Goodman LR, Goldberg J, Falcone T, Austin C, Desai N, et al. (2016) Does the addition of time-lapse morphokinetics in the selection of embryos for transfer improve pregnancy rates? A randomized controlled trial. Fertil Steril 105(2): 275-285.

20. Gleicher N, Metzger J, Croft G, Kushnir VA, Albertini DF, et al. (2017) A single trophectoderm biopsy at blastocyst stage is mathematically unable to determine embryo ploidy accurately enough for clinical use. Reprod Biol Endocrinol 15(1): 33.

21. Murtinger M, Wirleitner B, Schuff M (2018) Scoring of mosaic embryos after preimplantation genetic testing: a rollercoaster ride between fear, hope and embryo wastage. Reprod Biomed Online 37(1): 120-121.

22. Tesarik J (2018) Is blastomere multinucleation a safeguard against embryo aneuploidy? Bck to the future. Reprod Biomed Online.

23. Tesarik J, Greco E (1999) The probability of abnormal preimplantation development can be predicted by a single static observation on pronuclear stage morphology. Hum Reprod 14(5): 1318-1323.

24. (2018) Doubts about preimplantation genetic screening for aneuploidies: will liquid biopsy solve the problem? Gynecol Reprod Health 2(2): 1-5.

25. Balaban B, Yakin K, Urman B, Isiklar A, Tesarik J, et al. (2004) Pronuclear morphology predicts embryo development and chromosome 
constitution. Reprod Biomed Online 8(6): 695-700.

26. Leese HJ (2015) History of oocyte and embryo metabolism. Reprod Fertil Dev 27(4): 567-571.

27. Jones GM, Cram DS, Song B, Kokkali G, Pantos K, et al. (2008) Novel strategy with potential to identify developmentally competent IVF blastocysts. Hum Reprod 23(8): 1748-1759.

28. Menezo Y, Hazout A, Dumont M, Herbaut N, Nicollet B, et al. (1992) Coculture of embryos on Vero cells and transfer of blastocysts in humans. Hum Reprod 7 (Suppl 1): 101-106.

29. Hazout A, Benkhalifa M, Cell free DNA as a therapeutic target for female infertility and diagnostic marker. European Patent $n^{\circ} 13156626$.

30. Miravet-Valenciano JA, Rincon-Bertolin A, Vilella F, Simon C (2015)
Understanding and improving endometrial receptivity. Curr Opin Obstet Gynecol 27(3): 187-192.

31. Geenen V, Hauterive PDS, Puit M, Hazout A, Goffin F, et al. (2002) Autoimmunity and pregnancy: theory and practice. Acta Clin Belg 57(6): 317-324.

32. Gómez E, Ruíz-Alonso M, Miravet J, Simón C (2015) Human Endometrial Transcriptomics: Implications for Embryonic Implantation. Cold Spring Harb Perspect Med 5(7): a022996.

33. Miller EJ, Fraser IS (2015) The importance of pelvic nerve fibers in endometriosis. Womens Health (Lond) 11(5): 611-618.

\begin{tabular}{l} 
Your next submission with Juniper Publishers \\
will reach you the below assets \\
- Quality Editorial service \\
- Swift Peer Review \\
- Reprints availability \\
- E-prints Service \\
- Manuscript Podcast for convenient understanding \\
- Global attainment for your research \\
- Manuscript accessibility in different formats \\
( Pdf, E-pub, Full Text, Audio) \\
- Unceasing customer service \\
Track the below URL for one-step submission \\
https://juniperpublishers.com/online-submission.php \\
\hline
\end{tabular}

